\title{
Dynamic Response Analysis of Titanium Alloy Plate under Thermal Environment
}

\author{
Xuefeng ZOU \\ Aviation Key Laboratory of Aeronautical Acoustics and \\ Dynamics, Aircraft Strength Research Institute \\ Aircraft Strength Research Institute, AVIC \\ Xi'an China \\ zouxf1114@126.com
}

Dingwen GUO

Aviation Key Laboratory of Aeronautical Acoustics and Dynamics, Aircraft Strength Research Institute

Aircraft Strength Research Institute, AVIC

Xi'an China

guodingwen@126.com

\begin{abstract}
-surface structures of the vehicle suffer thermal loadings during the high speed flight. The thermal stress distribution of typical titanium alloy plate under thermal loadings is studied based on the assumption of uncoupled thermal-structural properties and nonlinear von Karman large-deflection strain-displacement relationship; the critical buckling temperature of simply supported titanium alloy plate is obtained through generalized eigenvalue analysis, and the change of the response characteristic before and after plate buckling is obtained by further analysis. The results show that, simply supported titanium alloy plate in uniform temperature field is prone to buckling because of the relatively low critical buckling temperature. The modal and frequency of the plate were changed before and after the buckling, structure shows more characteristics of higher order modes.
\end{abstract}

Keywords- Titanium alloy plate; thermal buckling; thermal stress; thermal modal analysis; dynamic response

\section{INTRODUCTION}

With the increasing speed of modern aircraft, vehicle surface is affected more and more serious by aerodynamic heating, aerodynamic heating issue has caused widespread concern, more thermal protection structures and composites, alloys are applied to high speed aircraft, where aerodynamic heating effect must be considered. The temperature of the surface structure will rise due to dynamic heating, and the structure will suffer thermal stress due to uneven distribution of temperature at the same time [1-2]. The Internal thermal stress will cause damage to the structure by changing the structural strength and stiffness and further affecting the vibration characteristics of the structure. Therefore, dynamic response characteristics of the structure under thermal environment become particularly important.

The dynamic response research of the aircraft structures developed with advances in aviation technology.

\author{
Li ZHANG \\ Aviation Key Laboratory of Aeronautical Acoustics and \\ Dynamics, Aircraft Strength Research Institute \\ Aircraft Strength Research Institute, AVIC \\ Xi'an China \\ lily2003@126.com
}

\section{Kai PAN}

Aviation Key Laboratory of Aeronautical Acoustics and Dynamics, Aircraft Strength Research Institute Aircraft Strength Research Institute, AVIC Xi'an China z6541212@126.com

In recent years, the researchers have gradually focused on the effects of the dynamic response of the aircraft structures caused by the thermal environment. Bhangale, et al [3], analyzed the thermal buckling problem of functionally graded beams by finite element method (FEM); Shi X M ,et al [4], analyzed transient temperature field and vibration characteristic of the structure underling thermal environment based on the NASTRAN software; Huang S Y, et al [5], analyzed the modes of tapered aluminum alloy platesin the non-uniform temperature field; Yang X W, et al [6], analyzed the vibro-acoustic dynamic characteristic of the aircraft structure.

In this paper, the object is a typical simply supported titanium alloy plate of the aircraft structure. Thermal stress of the plate under thermal environment is analyzed using FEM, the thermal mode characteristics under different temperature filed are obtained and thermal-acoustic response of the titanium alloy plate is calculated by farther analysis. Dynamic response variation with temperature is calculated finally.

\section{THE FINITE ELEMENT MODEL}

\section{A. Physical properties of the model}

The calculating model is a titanium alloy plate that measured $330 \mathrm{~mm} \times 395 \mathrm{~mm} \times 1.5 \mathrm{~mm}(a \times b \times h)$. Here a, b and $h$ are the length, width and thickness of the plate respectively, the model is shown in Fig .1. The material of the model is TC4, and its main physical properties are given in the Table I. 


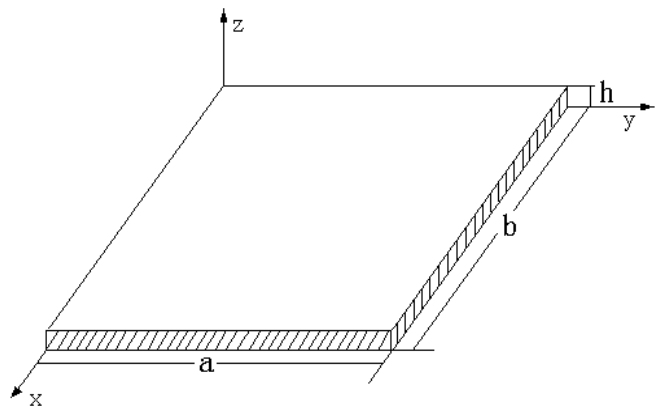

Figure 1. Geometry dimensions of the model

TABLE I. PHYSICAL CHARACTERISTICS OF TC4

\begin{tabular}{|c|c|c|c|c|}
\hline$\rho /\left(\mathrm{Kgm}^{-\mathbf{3}}\right)$ & $\alpha /\left({ }^{\circ} \mathrm{C}^{-\mathbf{1}}\right)$ & $\boldsymbol{C} /\left(\mathrm{Jkg}^{-\mathbf{1}}{ }^{\circ} \mathrm{C}^{-\mathbf{1}}\right)$ & $\boldsymbol{E} /(\mathrm{GPa})$ & $\boldsymbol{\mu}$ \\
\hline 4440 & $9.1 e^{-6}$ & 611 & 123.0 & 0.3 \\
\hline
\end{tabular}

B. The analysis process for the thermal-sturcture coupling problem

Thermal stress response analysis of the plate is a thermal-structure coupling problem. the detail process for solving thermal-structure problem is shown in Fig .2

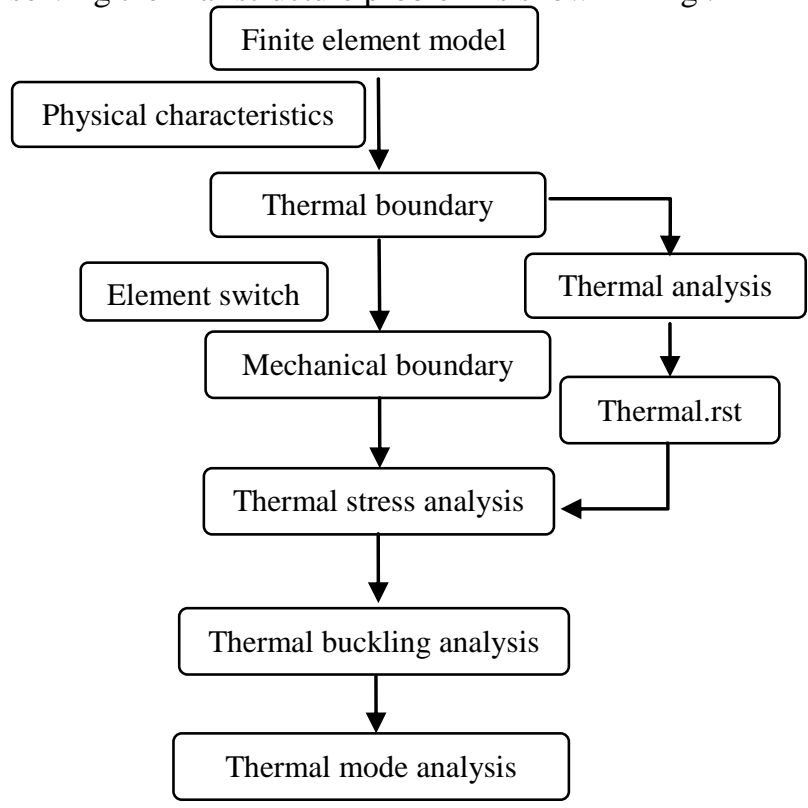

Figure 2. The analysis process for thermal-stucture coupling problem

\section{The finite element model}

The parametric modeling of the titanium alloy plate is completed using software ANSYS, in which the shell131 element is selected for the thermal element and shell181 for the corresponding structure element, the grid size is $5 \mathrm{~mm}$, the total number of the element is 25 , the finite element model is shown in Fig .3

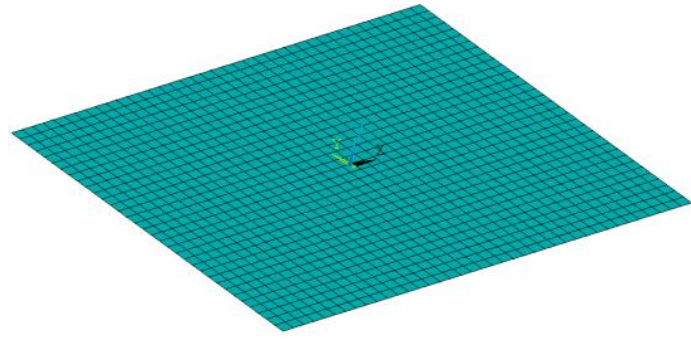

Figure 3. Finite element model of the plate

\section{THERMAL BUCKLING ANALYSIS}

Thermal stresses of the titanium alloy plate is calculated before the thermal buckling analysis, the eigenvalue analysis is conducted for obtaining the critical buckling temperatures, the first order critical buckling temperature is concerned generally [7-8].

For the simply supported plate structure of steady temperature field, the first order critical buckling temperature is calculated by the following theoretical calculation formula:

$$
T_{C}=\frac{\pi^{2} h^{2}}{12(1+\mu) \alpha b^{2}}\left(1+\frac{b^{2}}{a^{2}}\right)
$$

Where $\mathrm{a}, \mathrm{b}$ and $\mathrm{h}$ are the length, width and thickness of the plate respectively, $\mu$ is the poisson's ratio, $\alpha$ is the coefficient of thermal expansion.

\section{A. boundary and loading conditions}

The titanium alloy plate is simply supported at four edges, the initial temperature and the reference temperature are 20 , and a uniform temperature field of 50 is applied to the plate.

\section{B. Thermal stress analysis}

The sequential coupling method and the direct sparse matrix solver are adopted to calculate the thermal stress of the plate, the nonlinear characteristic is considered, shell 131 is used for thermal analysis and shell 181 is used for acoustic analysis. The displacement contours and stress contours are shown in Fig .4 and Fig .5 respectively.

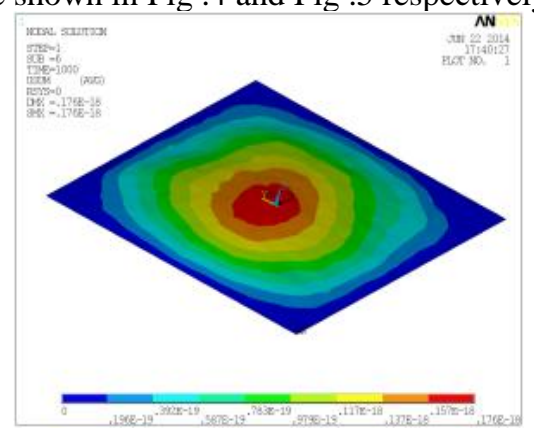

Figure 4. Displacement contours of the plate 


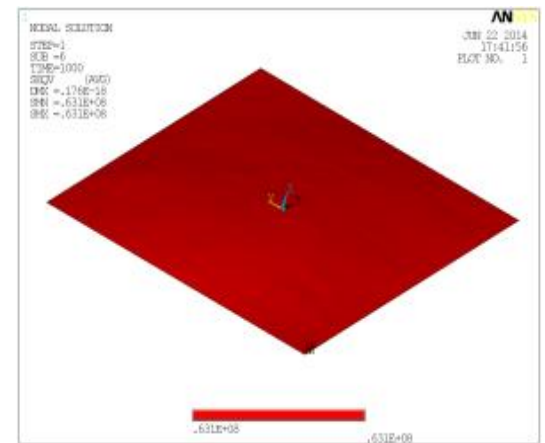

Figure 5. Stress contours of the plate

\section{Thermal buckling analysis}

Based on the thermal stress analysis, the first order critical buckling temperature of the plates in different thickness are calculated via the buckling analysis using nonlinear solver, the numerical results and the theoretical results are shown in Table II.

TABLE II. THE CRITICAL BUCKLING TEMPERATURE OF PLATE

\begin{tabular}{|c|c|c|c|}
\hline \multirow{2}{*}{ Thickness(mm) } & \multirow{2}{*}{ Load factor } & \multicolumn{2}{|c|}{$\boldsymbol{T}_{\boldsymbol{C}}\left({ }^{\circ} \mathrm{C}\right)$} \\
\cline { 3 - 4 } & & Theoretical & FEM \\
\hline 1.0 & 0.0392 & 21.05 & 21.05 \\
\hline 1.5 & 0.0881 & 22.36 & 22.36 \\
\hline 2.0 & 0.1566 & 24.20 & 24.20 \\
\hline 2.5 & 0.2447 & 26.56 & 26.56 \\
\hline 3.0 & 0.3523 & 29.45 & 30.00 \\
\hline
\end{tabular}

From Table II, we may safely draw a conclusion that the critical buckling temperature of the plates is relatively low, that is, the titanium alloy plate is easily bucked when its thermal deformation is constrained. When the thickness of the plates is $1.5 \mathrm{~mm}$, the first order critical buckling temperature of the plate is $22.36^{\circ} \mathrm{C}$, the first four order mode shapes of the plate in room temperature are shown in Fig.6.

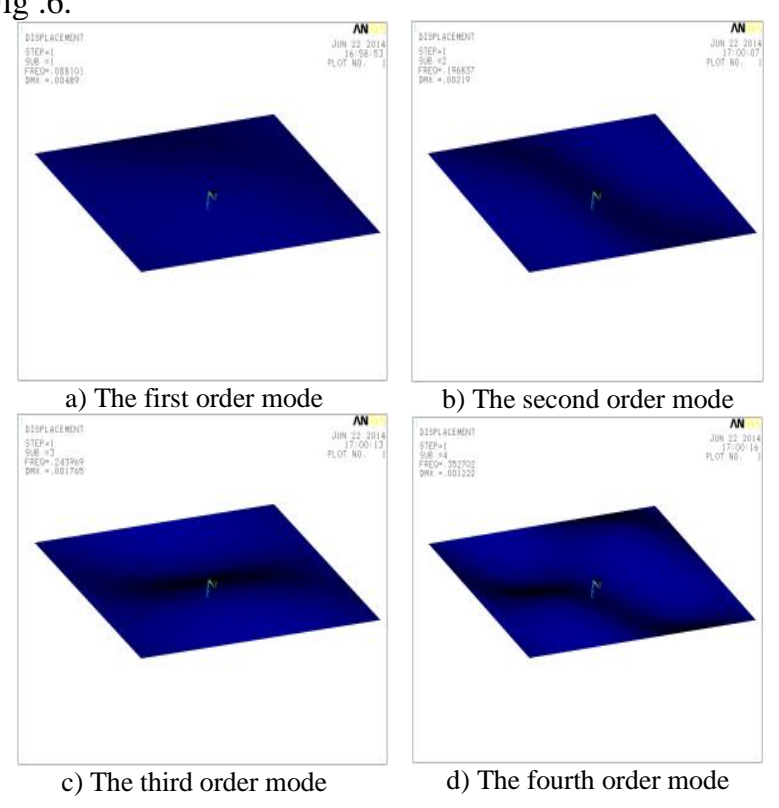

Figure 6. The first four order mode shapes of plate

\section{CHANGE OF MODE SHAPES BEFORE AND AFTER BUCKLING}

The natural frequencies of the structure change with temperature mainly reflected in following two aspects: temperature makes the material stiffness reduce; and the thermal stress caused by the temperature can be seen as pre-stress, which lead to change of the distribution of stiffness. Therefore, the vibration problem of the structure under the thermal loading requires enough attention [9-11].

The first order critical buckling temperature of the plate that has a thickness of $1.5 \mathrm{~mm}$ is $T_{c r}$, we can get $T_{c r}=22.36{ }^{\circ} \mathrm{C}$ through the previous calculation. Set the buckling coefficient [12]

$$
S=\frac{T-T_{r e f}}{T_{c r}-T_{r e f}}
$$

where $T_{r e f}$ is the reference temperature, $T_{r e f}=20^{\circ} \mathrm{C}$, it is obviously that, while $0<=S<1$, the plate is in the prebuckling state, while $S>1$, the plate is in the post buckling state, the first five order natural frequencies of the titanium alloy plate in different buckling coefficients $S=0.8$ 、 $S=1.0 、 S=1.6$ are calculated separately, the results are shown in Table III.

TABLE III. THE FIRST FIVE ORDER NATURAL FREQUENCIES OF THE TITANIUM ALLOY PLATE

\begin{tabular}{|l|c|c|c|c|c|}
\hline $\mathbf{S}$ & $\boldsymbol{f}_{\mathbf{1}} /(\mathbf{H z})$ & $\boldsymbol{f}_{\mathbf{2}} /(\mathbf{H z})$ & $\boldsymbol{f}_{\mathbf{3}} /(\mathbf{H z})$ & $\boldsymbol{f}_{\mathbf{4}} /(\mathbf{H z})$ & $\boldsymbol{f}_{\mathbf{5}} /(\mathbf{H z})$ \\
\hline 0.0 & 59.41 & 132.71 & 164.47 & 237.72 & 255.03 \\
\hline 0.6 & 37.57 & 113.50 & 145.56 & 219.18 & 236.55 \\
\hline 1.0 & 0.00 & 98.63 & 131.46 & 205.89 & 223.38 \\
\hline 1.6 & 70.00 & 106.87 & 184.18 & 202.02 & 288.53 \\
\hline
\end{tabular}

It can be seen from Table. 3 that natural frequency of the plate drops with the increase of temperature, the structure is in a critical buckling state and prone to snapthrough when the first order natural frequency drops to zero, the structure enters the post bucked state with the continue increase of the temperature, natural frequency increases until the next order critical buckling state because of the stress stiffness effect.

The mode shapes of the plate before and after buckling are calculated and shown in Fig .7 and Fig .8respectively.

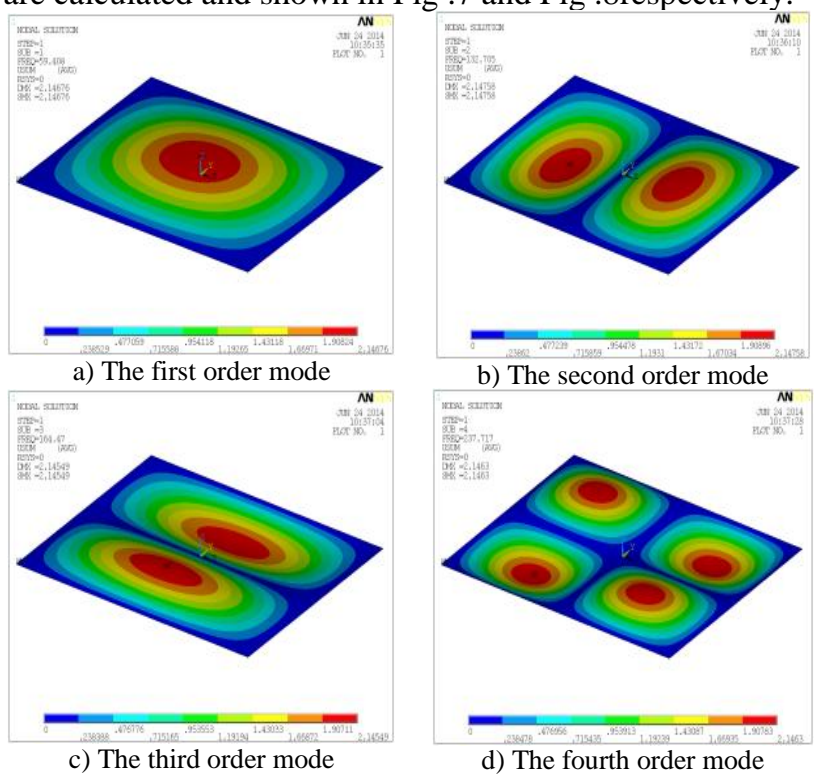

Figure 7. The mode shapes as $\mathrm{S}=0$ (pre-buckling) 


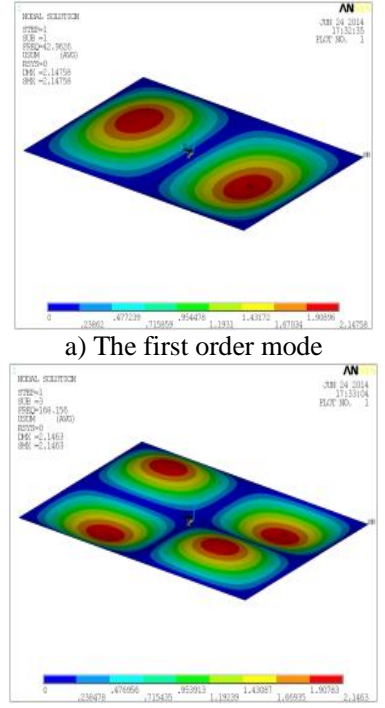

c) The third order mode

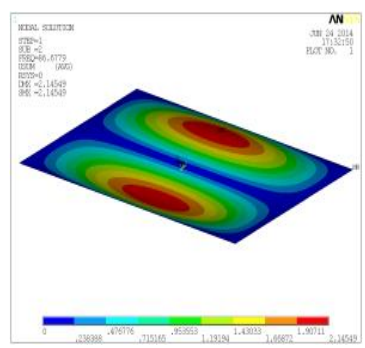

b) The second order mode

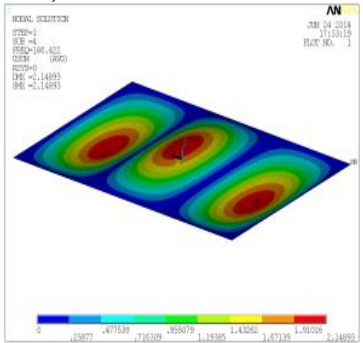

d) The fourth order mode
Figure 8. The mode shapes as $\mathrm{S}=2$ (post-buckling)

It can be obtained by comparative study of Fig .7 and Fig .8 that, change of the distribution of stiffness caused by thermal stress results in the change of the mode shapes, as the plate getting into the post buckling state, the first order mode shape of the plate in the pre-buckling state no longer appears, the dynamic response will be affected by the higher order modes.

\section{Conclusions}

In this paper, thermal buckling analysis, thermal mode analysis and thermal-acoustic response analysis of the titanium alloy plate based on the thermal-acoustic coupling model are conducted, the following conclusions are summarized:

For simply supported titanium alloy plate, it is easily into the buckling state because of the relatively low critical buckling temperature, accordingly, in order to determine whether the structure into the buckling state, the buckling temperature should be considered in the process of thermal-acoustic response analysis, and the nonlinear characteristics of the post buckling analysis should be considered (including non-linear and geometric nonlinear material);

The natural frequencies and mode shapes of the plate both change with the temperature, the natural frequencies of the pre-buckling plate drop with the rise of temperature, the mode shapes of the pre-buckling plate have no obvious changes; the first order natural frequency decrease to zero when temperature rises to the critical buckling point, the plate in prone to snap-through at present; the natural frequencies of the post buckling plate increase with the rise of temperature, the mode shape of the post-buckling plate has obvious changes, the dynamic response on the plate will be more effected by the higher order modes.

\section{REFERENCES}

[1] MCNAMARAJJ. Hypersonic Aero thermo elastic Studies for Reusable Launch Vehicles[R]. AIAA, 2004-1590, 2004.

[2] NIU Yao-bin, WANG Zhong-wei. Analysis of Tail Thermal Flutter Under Aerodynamic Heating[J]. Aircraft Design, 2009, 29(5):13-15.

[3] Bhangale R K, Ganesan N. Thermo-elastic buckling and vibration behavior of a functionally graded sandwich beam with constrained viscoelastic core[ J ]. J Sound Vib, 2006, 295 (1-2): 294 - 316.

[4] Shi X M, Yang B Y. Temperature field and mode analysis of flat panel with thermal environment of transient heating. Computer Aided Engineering, 2006, 15(S1):15-18.

[5] Huang S Y, Wang Z Y. The structure modal analysis with thermal environment. Missiles and Space Vehicle, 2009(5):50-56.

[6] Yang X W, Li Y M, Geng Q. Broadband vibro-acoustic response of aircraft in high temperature environment based on hybrid FE-SEA. Acta Aeronautical et Astronautic Sinica, 2011, 32(11):1851-1859.

[7] Thompson R C, Richards W L. Thermal-structure panel buckling tests.N92-15404, 1991.

[8] Marlana N. behnke, Anurag Shrma, Adam Przekop et al. Thermal-acoustic Analysis of a Metallic Integrated Thermal Protection System Structure[C].51st AIAA/ ASME/ ASCE/ AHS/ ASC Structures, Structural Dynamics, and Materials Conference < BR >18th 12-15 April 2010, Orlando ,Florida.

[9] Liao R D, Zuo Z X, Rong K L. Model analysis of solid missile tail with consideration of the effect of high temperature. Journal of mechanical Strength, 2003, 25(1):98-101.

[10] Vosteen B L F, McWithey R R, Thompson R G. Effect of transient heating on vibration frequencies of some simple wing structures. NACA TN-4054, 1960.

[11] Ribeiro P, Manoach E. The Effect of Temperature on the Large Amplitude Vibrations of Curved Beams [J].Journal of Sound and Vibration, 2005, 285(4/5):1093-1107.

[12] Tzou H S, Zhou Y H. Nonlinear piezo thermal elasticity and multi-field actuation, Part2: Control of nonlinear defection buckling and dynamics [J]. Transaction of the ASME: The Journal and Acoustics, 1997, 119: 382-389. 